\title{
Insights into Glucose Metabolism Inarchaea and Bacteria: Comparison Study of Embden-Meyerhof- Parnas (EMP) and Entner Doudoroff (ED) Pathways
}

\author{
Sultan F Alnomasy ${ }^{1 *}$ and Yousef S Al-Harbi ${ }^{2}$ \\ ${ }^{1}$ College of Applied Medical Science, Al- Quwayyah, Shaqra University, KSA \\ ${ }^{2}$ Al-Quwarah General Hospital, Al-Quwarah, Qassim, KSA
}

Submission: August 09, 2017; Published: August 30, 2017

*Corresponding author: Sultan F. Alnomasy, College of Applied Medical Science, Al- Quwayyah, Shaqra University, KSA,

Email: s.alnomasy@su.edu.sa

\begin{abstract}
Glucose is an important source for producing energy in all living organisms. Glucose metabolism is various among these living organisms through using different enzymes and modified pathways for metabolism of glucose due to their environment conditions. In this paper, we provide comparative opinion about how these living organisms such as bacteria and archaea process glucose for achieving their goals to produce energy.
\end{abstract}

Keywords: Glucose metabolism; Embden-Meyerhof-Parnas; Entner doudoroff

\section{Introduction}

Eukaryotes, bacteria and archaea are major living organisms on the earth and they are classified based on their universal small ribosomal RNA subunit [1]. These organisms have some difference in their structure and glucose metabolism. For example, archaea have a special composition in their membrane like a glycerol back bone of their membrane phospholipids and this composition is unique feature to archaea which is not found in any other organisms [2]. However, archaea and eukarya have primases, helicases and replicative polymerases which are parts of the DNA replication, whereas theses enzymes are not related to the bacterial replication system [3]. On other hand, bacteria and archaea have some similarities and differences in glucose metabolism. In this paper, we are compared the glucose metabolism between archaea and bacteria based on differences of enzymes and pathways in carbohydrate metabolism. This paper focused some differences and similarities in the classical Embden-Meyerhof-Parnas (EMP) and the Entner Doudoroff (ED) pathways that are found in bacteria and archaea. EMP and ED are central pathways for carbohydrate metabolism among these organisms. Some archaeal enzymes have some similarity with bacteria, but most archaeal enzymes have no similarity with classical glycolytic pathways in Bacteria [4].

\section{EMP Pathway among Bacteria and Archaea}

Most organisms metabolize glucose though the EMP pathway to generate ATP, pyruvate and NADH. The pentose phosphate pathway is needed for supplying the metabolic intermediates that are not available in the EMP pathway, such as paints-5-phosphate and erythrose-4-phosphate, and NAPDH. Reactions of glycolysis (EMP pathway) involves: first, phosphorylation of glucose (preparatory phase), isomerization to fructose-6-phosphate, and phosphorylation to fructose-I, 6-biphosphate. Second, cleavage of Fructose 1, 6 diphosphate to 2 3-C PGAL. Finally, formation of 3-C pyruvic acid (end product of glycolysis) [5]. Modified EMP pathway occurs In archaea which has additional features to be unique to archaea such as synthesis methane and presence a novel coenzyme for acetate and methane. For example, Pyrococcus furiosus grows at $100 \mathrm{C}$ and ferment carbohydrates to acetate and carbon dioxide. Glucose and fructose don't support the growth of Pyrococcus furiosus, but other carbohydrates like maltose transport to the cell and convert to glucose [6]. However, there are some differences between classical and modified of EMP pathways. The first difference is the phosphoryl donor in the hexokinase and fructokinase reactions appears to be not ATP but rather ADP. The second difference is that the enzyme which oxidizes glyceraldehyde-3-phosphate to 3-phosphoglycerate is 
ferredoxin-linked enzyme and is not NAD-linked enzyme. The other difference is that theoxidizes of pyruvate to acetyl-CoA and carbon dioxide are done by pyruvate: ferredoxin oxidoreductase [7].The other example of a modified EMP pathway in archaea is hyperthermophile Thermoproteus tenax. Modified EMP pathway of this organism is different from the classical EMP pathway that is characterized by some coenzymes such as a ferredoxindependent glyceraldehyde-3-phosphate oxidoreductase [8].

\section{ED Pathway among Bacteria and Archaea}

Alternate way for carbohydrate metabolism, which is break down the glucose into pyruvate by using a set of enzymes, which are differ from glycolysis or the pentose phosphate pathway [7].The features of the ED pathway are occurring only in prokaryotes and 6-phosphogluconate dehydratase and 2-keto3-deoxyphosphogluconate aldolase are used to create pyruvates from glucose. There are a few organisms utilizes ED pathway and they may lack enzymes essential for glycolysis such as phosphofructokinase-1. This pathway is found in Pseudomonas, Rhizobium, and Azotobacter. On other hand, there are two different modifications of the ED pathway in Archaea, a nonphosphorylative and a semi- phosphorylative version for carbohydrate catabolism [8,4].

Modified ED pathway of S. solfataricus is not only utilized glucose, but also utilized galactose. Glucose dehydrogenase enzyme and gluconate dehydrataseare catalyzed the glucose, orgalactose to 2-keto-3-deoxygluconate. In the nonphosphorylative ED branch, KD (P) G aldolase is cleaved the 2-keto-3-deoxygluconate into one molecule of pyruvate and one glyceraldehyde. After that glycerate formation from glyceraldehyde to gain another molecule of pyruvate by phosphoenol pyruvate [9].

\section{Conclusion}

In comparison to a long history of research on bacteria, the study of archaeal metabolism is relatively recent focus of attention and there have been many new findings that have proven a several metabolic features distinct from those of bacteria. Obviously use a variant of the reversible EMP pathway and two different modifications of the ED pathway (a nonphosphorylative and a semi- phosphorylative version) for carbohydrate catabolism which are differ from classical EMP and the ED pathways.

In EMP pathway is the most common pathway in all domains of life. These enzymes are enolase, glyceralde- hyde3-phosphate dehydrogenase, triosephosphate isomerase and phosphoglycerate kinase which are convert of glucose-6-P into pyruvate so these enzymes are universally distributed among archaea, bacteria and eukarya. Unique features of EMP pathway in archaea include: reduction of ferredoxin instance of NADH, very low ATP and unique enzymes which are pyruvate: ferredoxin oxidoreductase, non-orthologus PGMs and nonphosphorylating GAP dehydrogenase. For example, pyruvate: ferredoxin oxidoreductase which is oxidized the pyruvate to acetyl-CoA and carbon dioxide. Those enzymes are not found in bacteria and eukaryotes.

On the other hand, the ED pathway shows the Archaea have ability to utilize both glucose and galactose as a source for energy. There are two different modifications of the ED pathway in Archaea, a non-phosphorylative and a semi- phosphorylative version for carbohydrate catabolism. In conclusion, EMP pathway is well- conserved in bacteria and eukaryotes and ED pathway is occurring only in prokaryotes, while archaea have developed a unique variety of these pathways.

\section{References}

1. Woese CR, Kandler O, Wheelis ML (1990) Towards a natural system of organisms: proposal for the domains Archaea, Bacteria and Eucarya. Proc Natl Acad Sci U S A 87(12): 4576-4579.

2. Koga Y (2012) Thermal adaptation of the archaeal and bacterial lipid membranes. Archaea 2012: 789652.

3. Kehrer D, Ahmed H, Brinkmann H, Siebers B (2007) Glycerate kinase of the hyperthermophilic archaeon Thermoproteus tenax: new insights into the phylogenetic distribution and physiological role of members of the three different glycerate kinase classes. BMC Genomics 8: 301.

4. Kouril T, Wieloch P, Reimann J, Wagner M, Zaparty M, et al. (2013) Unraveling the function of the two Entner-Doudoroff branches in the thermoacidophilic Crenarchaeon Sulfolobus solfataricus P2. FEBS J 280(4): 1126-1138.

5. Kengen SW, De Bok FA, van Loo ND, Dijkema C, Stams AJ, et al. (1994) Evidence for the operation of a novel Embden-Meyerhof pathway that involves ADP-dependent kinase during sugar fermentation by Pyrococcus furiosus. J Biol Chem 269(26): 17537-17541.

6. Mukund S, Adams MW (1995) Glyceraldehyde-3-phosphate ferredoxin oxidoreductase, a novel tungsten-containing enzyme with a potential glycolytic role in the hyperthermophilic archaeon Pyrococcus furiosus. J Biol Chem 270(15): 8389-8392.

7. Entner N, Doudoroff M (1952) Glucose and gluconic acid oxidation of Pseudomonas saccharophila. J Biol Chem 196(2): 853-862.

8. Ahmed H, Ettema TJ, Tjaden B, Geerling AC, van der Oost J, et al. (2005) The semi-phosphorylative Entner-Doudoroff pathway in hyperthermophilic archaea: a re-evaluation. Biochem J 390(Pt 2): 529540.

9. Albers SV, Birkeland NK, Driessen AJ, Gertig S, Haferkamp P, et al. (2009) SulfoSYS (Sulfolobus Systems Biology): towards a silicon cell model for the central carbohydrate metabolism of the archaeon Sulfolobus solfataricus under temperature variation. Biochem Soc Trans 37(Pt 1): 58-64. 


\section{Your next submission with Juniper Publishers} will reach you the below assets

- Quality Editorial service

- Swift Peer Review

- Reprints availability

- E-prints Service

- Manuscript Podcast for convenient understanding

- Global attainment for your research

- Manuscript accessibility in different formats ( Pdf, E-pub, Full Text, Audio)

- Unceasing customer service

Track the below URL for one-step submission https://juniperpublishers.com/online-submission.php 